Vol.15, No. 57, October, 2020, 1074-1091

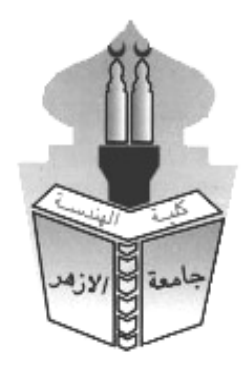

\title{
SIMULATION BETWEEN IN-SITU PILE LOAD TEST AND NUMERICAL ANALYSIS OF LARGE DIAMETER BORED PILE IN PORT SAID EAST PORT-EGYPT
}

\author{
Sahar Adel El-meligy*, Adel Gabr, and Waleed EL-Sekelly \\ Department of Structural Engineering, Faculty of Engineering, Mansoura University, \\ Mansoura, Egypt. \\ *Corresponding Author E-mail: saharade11592@gmail.com
}

\begin{abstract}
:
At the end of 2015, Suez Canal Authority and Ministry of defense planned the construction of a new container terminal at east of Port Said port. The project comprises the construction of approximately $2.5 \mathrm{KM}$ of new quay wall fully equipped to accommodate large container vessels. large diameter bored piles ( $\sim 72 \mathrm{~m}$ in length and $1.20 \mathrm{~m}$ in diameter) were used to transmit the load to the soil safely. According to several international codes and foundation design standards, field loading tests are the most effective way to evaluate the pile's bearing load capacity. However, loading until failure is hard to achieve. In this paper, numerical analysis using (PLAXIS 2D, V8.2) was carrying out to simulate load-displacement curve of load test for large diameter bored piles at the location of Port Said East Port, Egypt, as well as, (All Pile, V.6) which is relied on (p-y) analysis curve. Avery good match was observed between numerical analysis using PLAXIS and the pile load tests in loading-unloading cycles along the pile shaft and the percentage of compatibility is about $95 \%$. In contrast to PLAXIS, there are a significant difference between the results of All pile program and pile load test and the percentage of match is approximately $75 \%$.
\end{abstract}

\section{KEYWORDS: Load-Displacement Curve, Large pile diameter, Bored Piles, 2D-Plaxis program, All Pile program.}

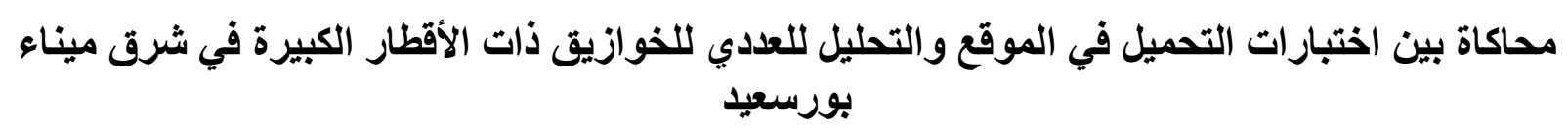

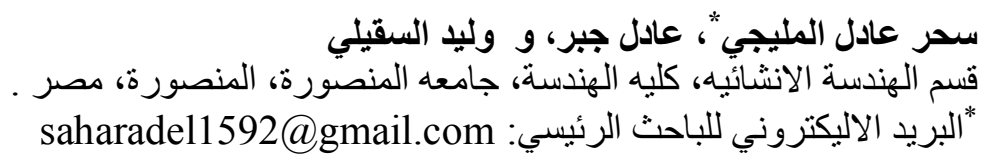

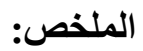

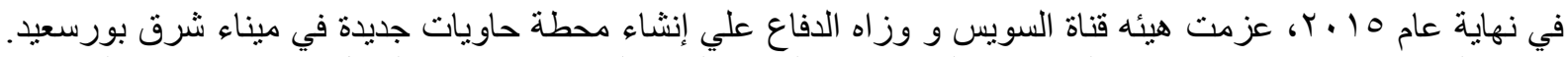

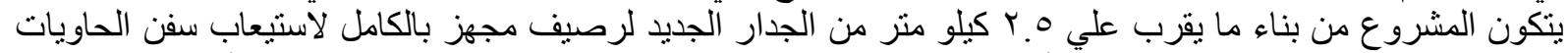

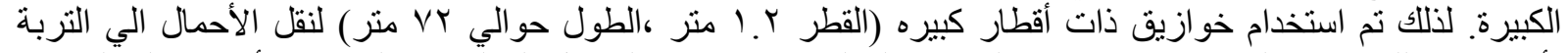

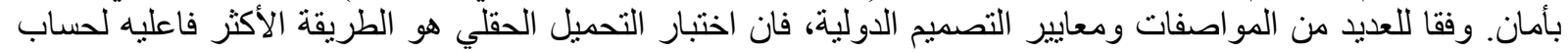

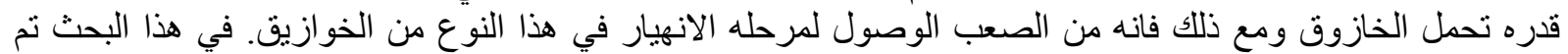

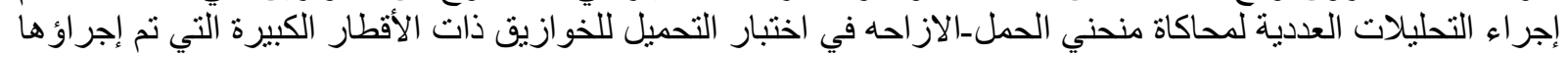




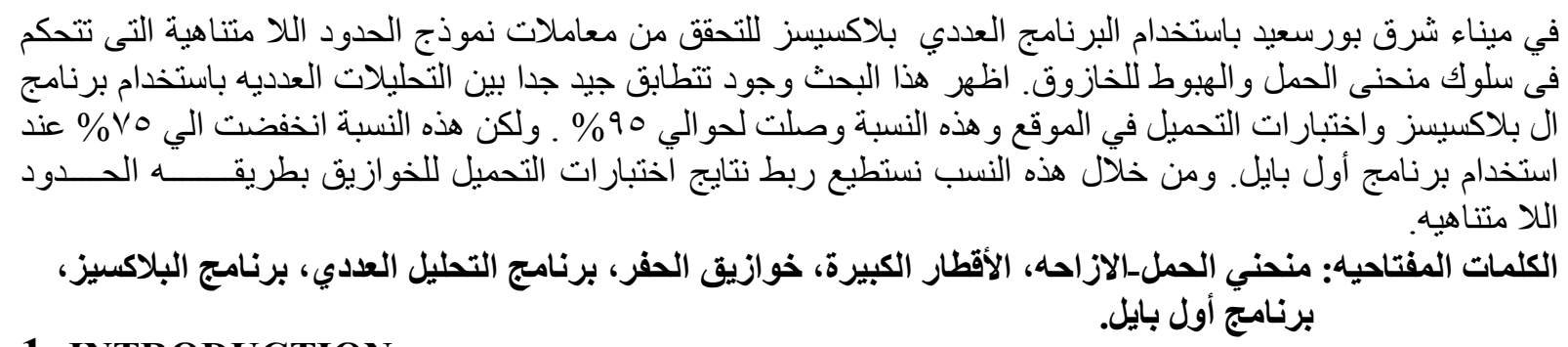

Large diameter bored piles are qualified to be the most powerful element of deep foundations implemented in many types of heavy loaded structures such as the high-rise buildings, offshore ports, wind power mills, storage silos. They are employed most frequently both to support heavy loads and to minimize settlement (O'Neill and Reese, 1999), ( Eid et al, 2019) .The in-situ full scale pile loading test is the most recommended methodology in several international geotechnical codes and foundation design standards ((ECP 202/4, 2005), (DIN 4014, 1990) and (AASHTO, 1998)) to evaluate the ultimate carrying capacity of large diameter bored piles in spite of its high cost as well as time consumption. The Egyptian code of practice (ECP 202/4, 2005), recommends to use the in-situ pile loading test for evaluating the ultimate capacity of large diameter bored pile. However, loading of large diameter bored piles, till achieving apparent failure is practically hard to achieve. This may be the reason why the measured pile load-settlement curves for large diameter bored piles usually do not show an apparent failure point.

Recently, finite element calculations and numerical analyses have risen in geotechnical problems for design foundation. In this paper, finite element model is used to simulate results of in-situ large diameter pile load test under loading-unloading cycles.

\section{SITE UNDER INVESTIGATION}

Port Said is located on the Egyptian Mediterranean north eastern cost of the Nile Delta approximately $70 \mathrm{~km}$ of Damietta port. The project comprises the construction of approximately $2.5 \mathrm{~km}$ of new quay wall fully equipped to accommodate large container vessels. The study area consists of two zones 4 and 5 as shown in Figure (1). Fortunately, all piles have the same length and diameter $72 \mathrm{~m}$ and $1.2 \mathrm{~m}$ respectively according to stratification of soil in boreholes.

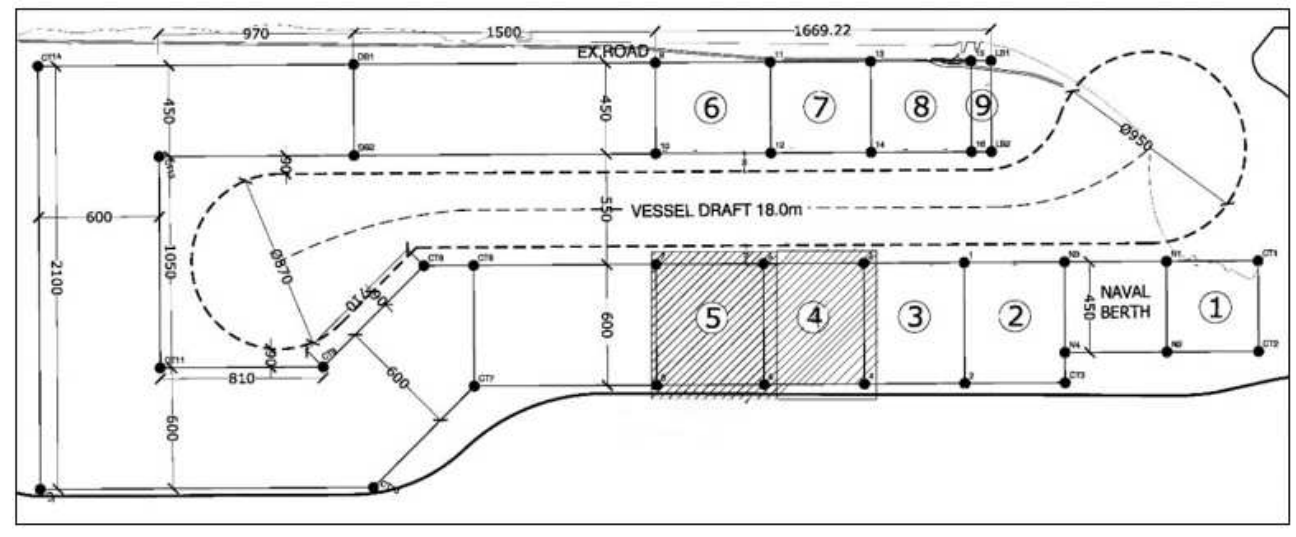

Fig (1) location of zones 4 and 5 under study.

\section{SOIL PROFILES AT LOCATIONS OF BOREHOLES}

In order to provide preliminary information of the soil layers, geotechnical investigation was carried out. Several boreholes were extended down to $100 \mathrm{~m}$ deep till reaching a layer that could support the applied load properly. Figure (2), demonstrates the soil profile classification for boreholes under study (B.H: 2, 3, 4, 6, 7, 9 and 10). 

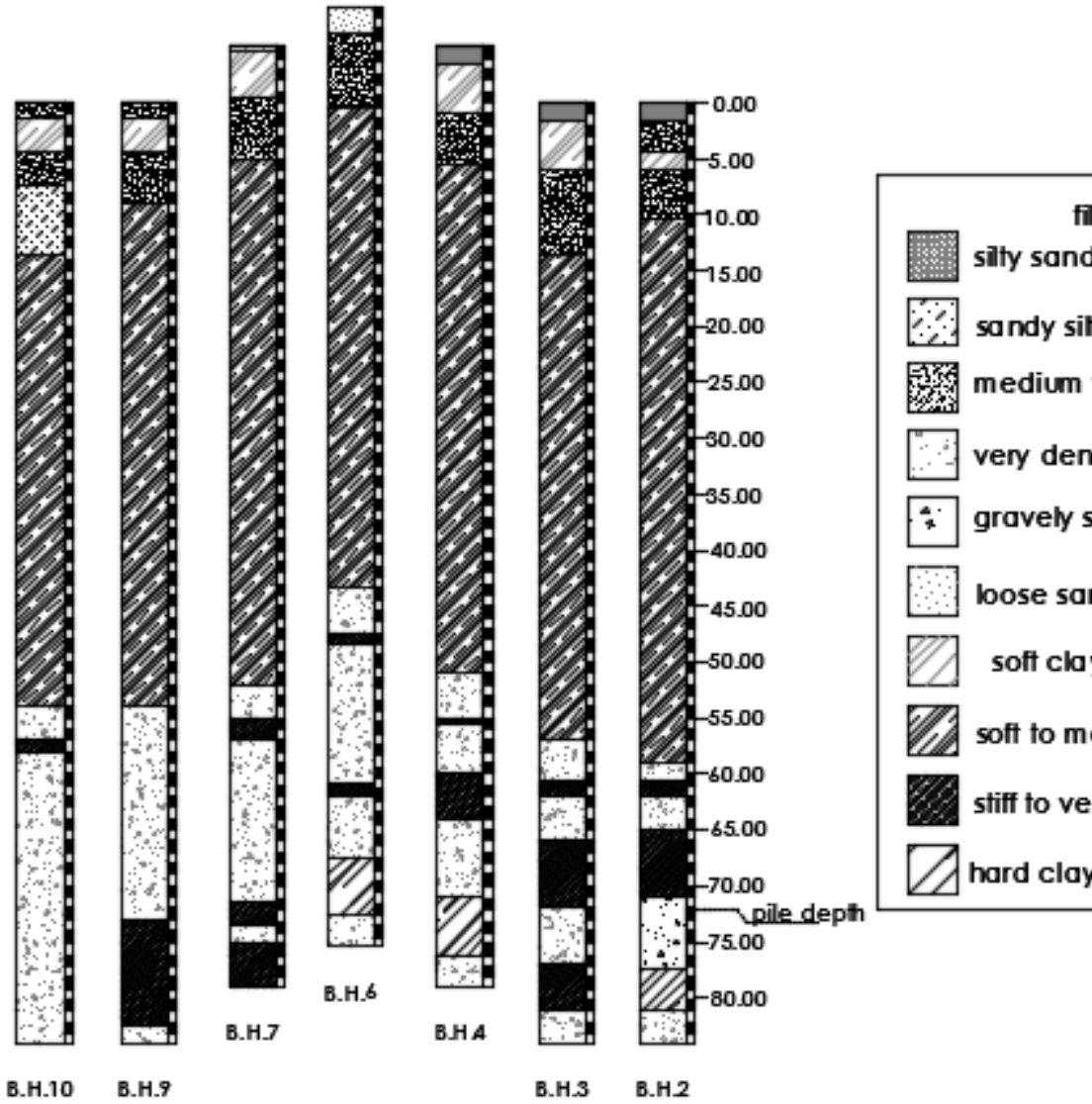

\section{fill}

silty sand with gravel

$\because$ sandy silt

厚紧 medium to fine sand

$-2500$

very dense sand

*. gravely sand very dense

loose sand

soft clay

soft to medium clay

stiff to very stif clay

$\triangle$ hard clay

Fig (2) Soil stratigraphy for boreholes.

\section{ESTIMATION OF ULTIMATE BEARING CAPACITY OF BORED PILE}

Due to the importance of pile foundation in transferring the structural load to the bearing ground located deep below ground surface, various methods are used to determine the ultimate bearing capacity ( $\left.Q_{u l t}\right)$ of a single vertical pile either field method or theoretical equations such as:

- Field load tests (pile load test at the site).

- Dynamic method (pile driving formulae).

- Correlation use of SPT and CPT values.

- The use of static bearing capacity equations.

To ascertain the field performance and evaluate the load carrying capacity, in-situ pile load tests are commonly used reliably.

In situ pile load test:

The tests loads are applied using a hydraulic jack which pushes on a reaction frame, with sufficient reaction capacity to perform tests, as shown in Figure (3). 


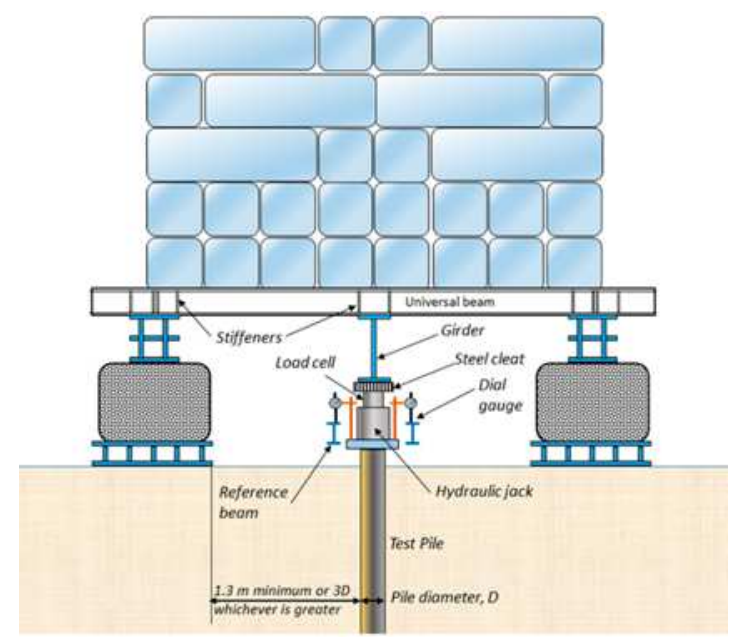

Fig (3) Device instruments for pile load test (Moayedi, 2019)

The tested pre-construction piles were loaded up to $26000 \mathrm{kN}$, representing $200 \%$ of the specified allowable pile load which is $13000 \mathrm{kN}$. The timing of loading and unloading stages, and corresponding time duration are according to (ASTM-D1143).

\section{NUMERICAL MODELING}

Numerical analysis was used to study the load-settlement behavior and failure load for large diameter bored pile under vertical loads is applied at the pile head using the commercial software (PLAXIS 2D-V8.2) (Brinkgreve and Broere, 2004) as well as, (All pile V.6) program which is relied on ( $p-y)$ analysis curve.

\subsection{PLAXIS model}

\subsubsection{Geometry and boundary conditions}

Two-dimensional axisymmetric finite element method was constructed using "PLAXIS 2D " after several trials to ensure all soil conditions are taken into account. The model height was $140 \mathrm{~m}$ and the model width was $70 \mathrm{~m}$, as shown in Figure (4). The external boundary conditions of the model were generated according to the following rules:

- The right and left edge were fixed in horizontal direction and free to move in the vertical $\left(\mathrm{U}_{\mathrm{X}}=0\right)$.

- The bottom boundary was fixed in two directions, $\left(\mathrm{U}_{\mathrm{X}}=\mathrm{U}_{\mathrm{Y}}=0\right)$.

- The top boundary was free in both directions. 


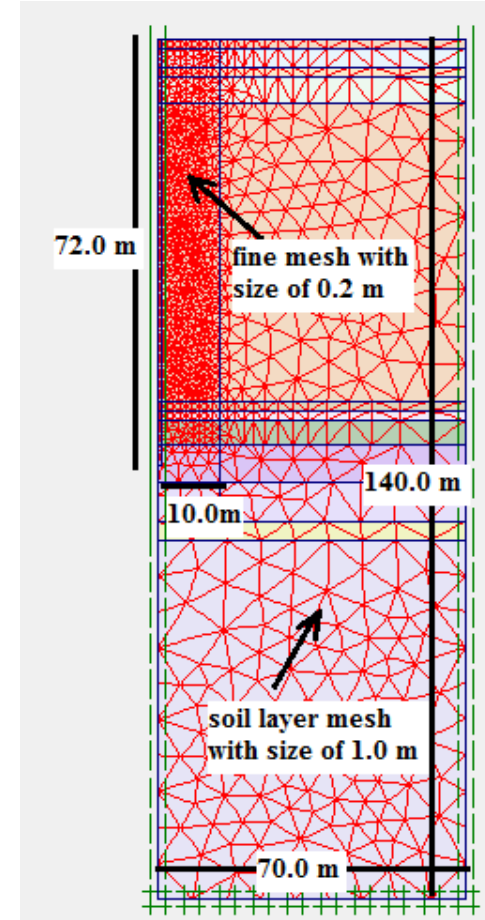

Fig.4: Geometry dimensions and boundary conditions of finite element model.

\subsubsection{Properties of the Pile Model}

Two-dimensional triangular elements "15 nodes" were selected to model the pile shaft. The material model used was Linear elastic model following Hooke's Law of isotropic linear elasticity. For accurate base resistance, the model needs at least two or three elements at the pile tip to get rid of the mesh dependency (Wehnert and Vermeer, 2004). Characteristic compressive strength ( $\mathrm{f} \mathrm{cu}$ ) of $350 \mathrm{~kg} / \mathrm{cm}^{2}$ was obtained in field after 28 curing days. According to this value, Young's modulus of elasticity could be determined according to Egyptian code of practice (ECP 202/4, 2005) from this relation refer to Eq. 1

$$
\mathrm{E}=14000 \sqrt{f_{\text {cu }}} \mathrm{kg} / \mathrm{cm}^{2}
$$

Summary of the pile properties are shown in Table 1.

Table 1: Structural parameters of large diameter bored pile.

\begin{tabular}{|r|c|}
\hline Parameters of piles & Values \\
\hline Pile diameter (D) & $1.2 \mathrm{~m}$ \\
\hline Pile length $(\mathrm{L})$ & $72 \mathrm{~m}$ \\
\hline Young's modulus (E $\left.\mathrm{E}_{\text {elastic }}\right)$ & $26^{*} 10^{6} \mathrm{kN} / \mathrm{m}^{2}$ \\
\hline Poisson's ratio $(\mathrm{v})$ & 0.2 \\
\hline Unit weight $(\gamma)$ & $25 \mathrm{kN} / \mathrm{m}^{3}$ \\
\hline
\end{tabular}

\subsubsection{Properties of the Soil Model}

The soil was modeled using (15-noded) Triangular elements. Different sizes were used to investigate the sensitivity of the soil mesh refinement and its effect on the results. Good progress was observed in stress and settlement results when fine mesh (with size of less than $0.2 \mathrm{~m}$ ) was used. However, analysis time significantly increased. As a compromise, the zone of very fine mesh with size of $0.2 \mathrm{~m}$ was considered around and below the pile $(10 \mathrm{~m} \times 77 \mathrm{~m})$. Gradually, soil mesh size is increased to be $1.0 \mathrm{~m}$ at boundaries locations.

Hardening-soil model is an advanced model for simulation the soil behavior; the soil stiffness is described by three types of elasticity moduli: the oedometer loading stiffness $\mathrm{E}_{\text {oed, }}$ triaxial 
loading stiffness $\mathrm{E}_{50}$ and triaxial unloading stiffness $\mathrm{E}_{\mathrm{ur}}$. Almost practical cases consider that, $E_{u r}$ is equal three times of $E_{50}$ while $E_{\text {oed }}$ value is equal to $E_{50}$ (Teshome and Ismail, 2011). The dilatancy angle $(\psi)$ is usually estimated when the internal angle of friction $(\varphi)$ is more than $30^{\circ}$, from the relation $\psi=\varphi-30^{\circ}$. The coefficient of lateral earth pressure $\left(\mathrm{k}_{\mathrm{o}}\right)$ is the most important and difficult parameter to determine (Kulhawy, 1991). A simplified relationship to calculate $\mathrm{k}_{\mathrm{o}}$ based on soil the friction angle $(\varphi)$ and the over consolidation ratio (OCR) is given by Eq. 2 (Kulhawy and Mayne, 1991):

$$
\mathrm{k}_{\mathrm{o}}=(1-\sin \varphi) \mathrm{OCR} \sin \varphi
$$

Based on geologic and construction history at site location, $\mathrm{OCR}=1$ is suitable value to be used in the equation. Drained condition was used to represent sand soil with no excess pore pressures are generated and undrained condition for clay soil with a full development of excess pore pressures.

Table 2, illustrates mechanical properties of soil layers according to Egyptian code of practice (ECP 202/3, 2005) for both sand (related to N value for SPT test) and clay. Young modulus $\mathrm{E}_{\mathrm{s}}$ for sand is usually calculated according to the following specific formulas and recommended correlations by the Egyptian code (ECP 202/3, 2005):

- For silty sand soil, Es $=4 \mathrm{~N} \mathrm{~kg} / \mathrm{cm}^{2}$

- For medium to fine sand soil, Es $=7 \mathrm{~N} \mathrm{~kg} / \mathrm{cm}^{2}$

- For dense sand soil, Es $=10 \mathrm{~N} \mathrm{~kg} / \mathrm{cm}^{2}$

Table 2: Mechanical properties of soil layers.

\begin{tabular}{|c|c|c|c|c|c|c|c|c|}
\hline soil layers & 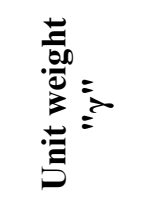 & 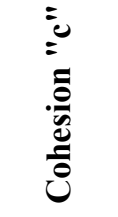 & 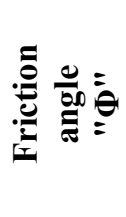 & 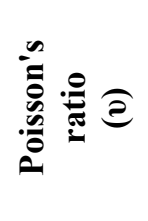 & 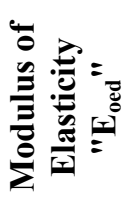 & 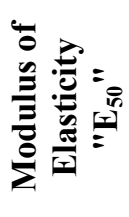 & 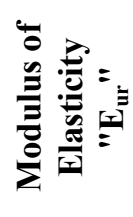 & ه \\
\hline Units & $\mathrm{kN} / \mathrm{m}^{3}$ & $\mathrm{kN} / \mathrm{m}^{2}$ & $\mathbf{0}$ & ---- & $\mathrm{MN} / \mathrm{m}^{2}$ & $\mathrm{MN} / \mathrm{m}^{2}$ & $\mathrm{MN} / \mathbf{m}^{2}$ & --- \\
\hline $\begin{array}{r}\text { Medium - } \\
\text { Stiff clay }\end{array}$ & 18.1-20.6 & $50-80$ & ---- & $0.35-0.4$ & $12-18$ & 12- 18 & 36- 54 & \multirow{2}{*}{1} \\
\hline $\begin{array}{r}\text { Stiff - } \\
\text { Hard clay }\end{array}$ & $20.6-21$ & $80-200$ & --.-' & $0.3-0.35$ & 18- 40 & $18-40$ & $54-120$ & \\
\hline $\begin{array}{r}\text { Medium } \\
\text { sand }\end{array}$ & $17.5-18.5$ & 1 & $25-30$ & 0.3 & 25-30 & $25-30$ & $75-90$ & $.5-.57$ \\
\hline $\begin{array}{r}\text { Dense } \\
\text { sand }\end{array}$ & $18.5-19.5$ & 1 & $36-40$ & $0.25-0.3$ & 3- 60 & $30-60$ & $90-180$ & $.43-.5$ \\
\hline
\end{tabular}

\subsubsection{Parameters for Interface Elements}

An elastic-plastic model is used to describe the behaviour of interfaces for the modeling of soil-structure interaction. When the interface is elastic then both slipping (relative movement parallel to the interface) and gapping or overlapping (relative displacement perpendicular to the interface) could be expected to occur. The displacement magnitudes are illustrated in equations "(4)" and "(5)" (PLAXIS 2D-V8.2):

$$
\text { gap displacement }=\frac{\sigma \cdot t i}{\text { Eoedi }}
$$




$$
\text { slip displacement }=\frac{\tau \cdot t i}{G i}
$$

where,

$\sigma:$ the strength of the soil (ultimate shear stress) $\left[\mathrm{kN} / \mathrm{m}^{2}\right]$.

$\mathrm{G}_{\mathrm{i}}$ : Shear modulus of interface $\left[\mathrm{kN} / \mathrm{m}^{2}\right]$.

$\mathrm{E}_{\text {oedi }}$ : Compression modulus of interface $\left[\mathrm{kN} / \mathrm{m}^{2}\right]$.

$\mathrm{t}_{\mathrm{i}}$ : virtual thickness of the interface factor (Ranges between 0.01 to 0.1 ).

The Coulomb criterion is used to distinguish between elastic behavior, where small displacements can occur within the interface, and plastic interface behavior when permanent slip may occur. Moreover, shear strength parameters of the interface elements are linked to the strength of the adjacent layers of soil through a strength reduction factor (R). as represented by equation (6):

$$
\begin{aligned}
& \mathrm{C}_{\mathrm{i}}=\mathrm{R}^{*} \mathrm{C}_{\text {soil }} \\
& \tan \varphi_{\mathrm{i}}=\mathrm{R}^{*} \tan \varphi_{\text {soil }} \\
& \Psi_{\mathrm{i}}=0^{\circ} \text { for } \mathrm{R}<1, \text { otherwise } \Psi_{\mathrm{i}}=\Psi_{\text {soil }}
\end{aligned}
$$

Where,

$\varphi_{\mathrm{i}}$ : Angle of friction for the interface. $\left[{ }^{\circ}\right]$

$\mathrm{C}_{\mathrm{i}}$ : Effective adhesion for the interface. $\left[\mathrm{kN} / \mathrm{m}^{2}\right]$

$\Psi_{\mathrm{i}}$ : Angle of dilatancy for the interface..$\left.^{\circ}\right]$

In this research, a sensitivity analysis was performed for the parameter $\mathrm{R}$ based on the comparison between the settlement in pile load tests and finite element results. The best comparison was observed when the reduction factor of shear strength $(\mathrm{R})$ was (1.0).

\subsection{All Pile Program Model}

All Pile program analyzes all types of pile load capacity efficiently and accurately. Additionally, define new pile types and input customized parameters based on local practices and experience.

This program capable of preforming the calculation of vertical load and settlement by using two method of analysis: Vesic method and Reese method.

Reese method is the method used to calculate settlement of the pile and corrected $\mathrm{N}$ value for

\begin{tabular}{|c|c|c|}
\hline Soil classification & $\begin{array}{l}\text { Unit weight } \\
\mathrm{kN} / \mathrm{m}^{3}\end{array}$ & $\underset{\mathbf{k N} / \mathbf{m}^{2}}{\text { Cohesion "C" }}$ \\
\hline Soft & $16.3-18$ & $8-12$ \\
\hline Medium- stiff & $18.1-20.6$ & $25-30$ \\
\hline stiff - very stiff & $20.6-21$ & $80-120$ \\
\hline
\end{tabular}
SPT test was used to input the parameter of soil. Tables 4, 5 and 6 show the parameters are needed in All pile program for the pile and the soil:

Table 3: Soil properties for clay soils in All Pile program.

Table 4: Soil properties for sand soils in All Pile program. 


\begin{tabular}{|l|c|c|c|}
\hline Soil classification & $\begin{array}{c}\text { N1 value for } \\
\text { SPT }\end{array}$ & $\begin{array}{c}\text { Unit weight } \\
" \gamma{ } \mathbf{~ k N / \mathbf { m } ^ { 3 }}\end{array}$ & $\begin{array}{c}\text { Friction } \\
\text { angle } \boldsymbol{\Phi}\end{array}$ \\
\hline Loose sand & $3.0-10.0$ & $16.4-17.5$ & $20-25$ \\
\hline Medium & $10.0-25$ & $17.5-18.5$ & $25-30$ \\
\hline Dense & $26-50$ & $18.5-20$ & $36-40$ \\
\hline
\end{tabular}

Table 5: pile specifications in All Pile program.

\begin{tabular}{|l|c|}
\hline pile type & Drilled shaft D $>60 \mathrm{~cm}$ \\
\hline pile length " $\mathbf{L}$ " & $72 \mathrm{~m}$ \\
\hline pile diameter "D" & $1.20 \mathrm{~m}$ \\
\hline total area "At" & $1.13 \mathrm{~m}^{2}$ \\
\hline modulus of elasticity "E" & $26^{*} 10^{3} \mathrm{MN} / \mathrm{m}^{2}$ \\
\hline Inertia "I" & $10.18^{*} 10^{6} \mathrm{~cm}^{4}$ \\
\hline
\end{tabular}

\section{RESULTS AND ANALYSIS:}

By using numerical model and static load test, the performance of the pile for loadingunloading cycles and the ultimate bearing capacity as well as maximum deflection were predicted seven boreholes and loading tests for Port Said East Port were chosen for the comparison of the results. According to Egyptian code of deep foundation (ECP 202/4, 2005), if in-situ pile loading test results did not show apparent failure values, the ultimate load of the piles can be estimated as the average values that are obtained from Brinch Hansen 's 90 percent criterion (1963and Modified Chin 's method (1970). Table 6 illustrates the results of in-situ pile loading tests as well as the required details of each pile such as lengths, diameters, design loads and ground water table level.

Table 6: Results of Static load tests.

\begin{tabular}{|c|c|c|c|c|c|c|c|c|}
\hline \multirow{2}{*}{ 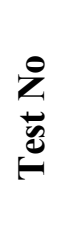 } & \multirow{2}{*}{ 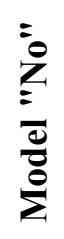 } & \multirow{2}{*}{ 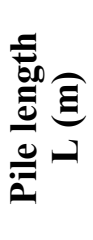 } & \multirow{2}{*}{ 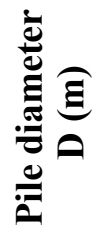 } & \multirow{2}{*}{ 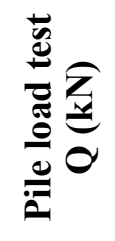 } & \multirow{2}{*}{ 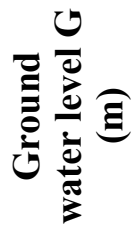 } & \multicolumn{3}{|c|}{ Predicted ultimate load } \\
\hline & & & & & & 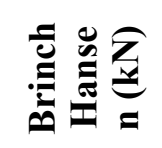 & 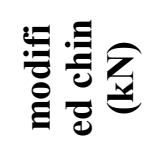 & 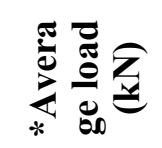 \\
\hline 1 & 2 & 72 & 1.20 & 7500 & 2.10 & 15667.40 & 14685.70 & 15175.50 \\
\hline 2 & 3 & 72 & 1.20 & 7500 & 2.80 & 13596.50 & 12746.70 & 13171.60 \\
\hline 3 & 4 & 72 & 1.20 & 10000 & 1.75 & 15788.20 & 14808.40 & 15298.30 \\
\hline 4 & 6 & 72 & 1.20 & 7500 & 1.00 & 12138.40 & 11379.00 & 11758.70 \\
\hline 5 & 7 & 72 & 1.20 & 10000 & 2.00 & 25823.20 & 24209.00 & 25016.10 \\
\hline 6 & 9 & 72 & 1.20 & 7500 & 3.00 & 18767.20 & 17594.30 & 18180.75 \\
\hline 7 & 10 & 72 & 1.20 & 7500 & 3.50 & 31784.00 & 29797.50 & 30790.75 \\
\hline
\end{tabular}


The following Figures show the load-settlement results of the field static load test, along with the extrapolation of the results using Brinch-Hansen method recommended by the ECP. Model number 4 and 7 were loaded up to $10000 \mathrm{kN}$ (2 Q $\left.\mathrm{Q}_{\text {design }}\right)$ but anther models were loaded up to $7500 \mathrm{kN}\left(1.5 \mathrm{Q}_{\text {design }}\right)$ according to the field data. The figures also show the results of the numerical simulation for PLAXIS and All pile programs for the same pile. The figures show excellent comparison between measured and numerically predicted results using PLAXIS but, there is a big difference between All pile predictions and field loading tests.

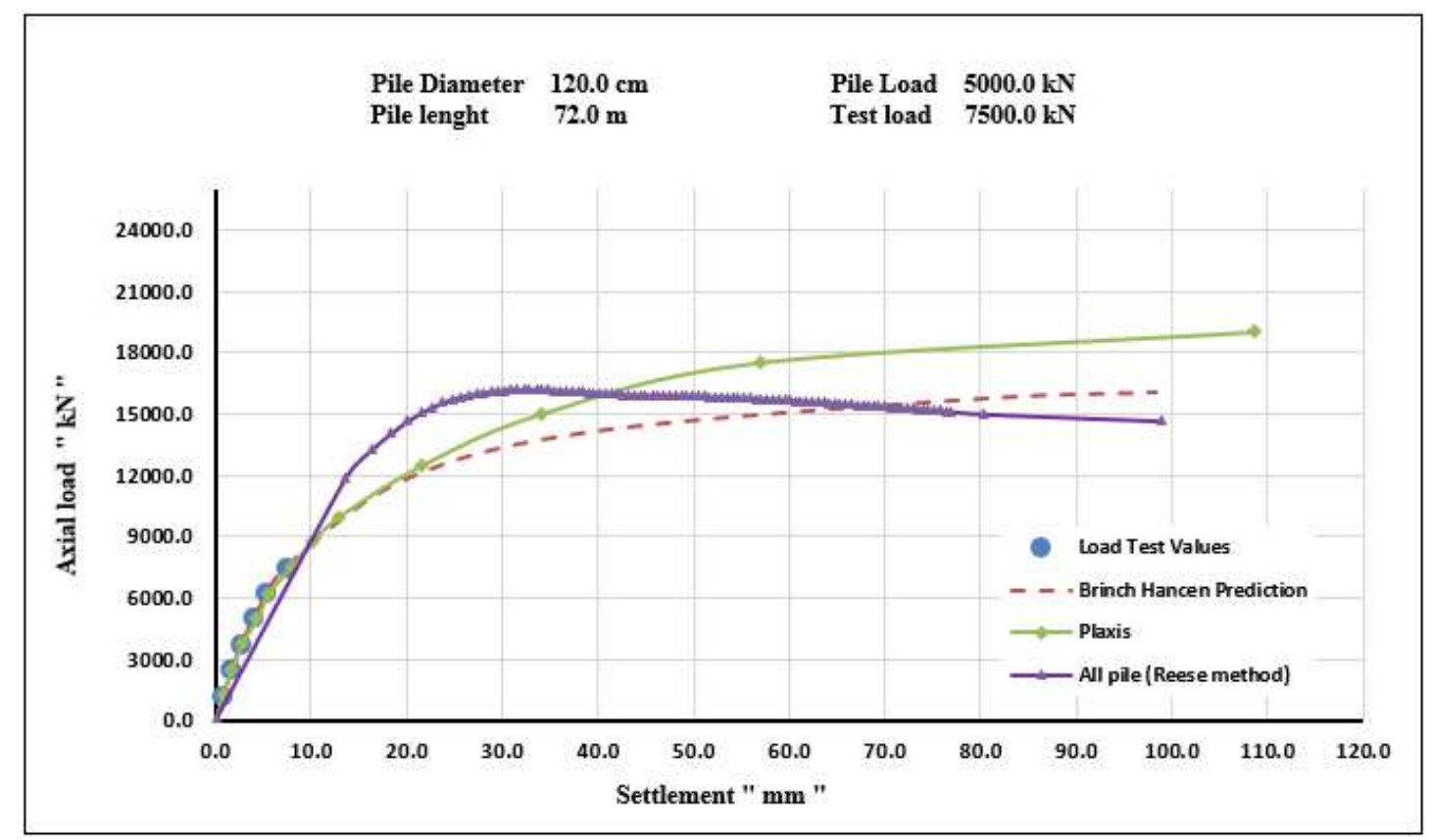

Fig. 4: Comparison between field test and finite element analysis in loading cycle for model No 1

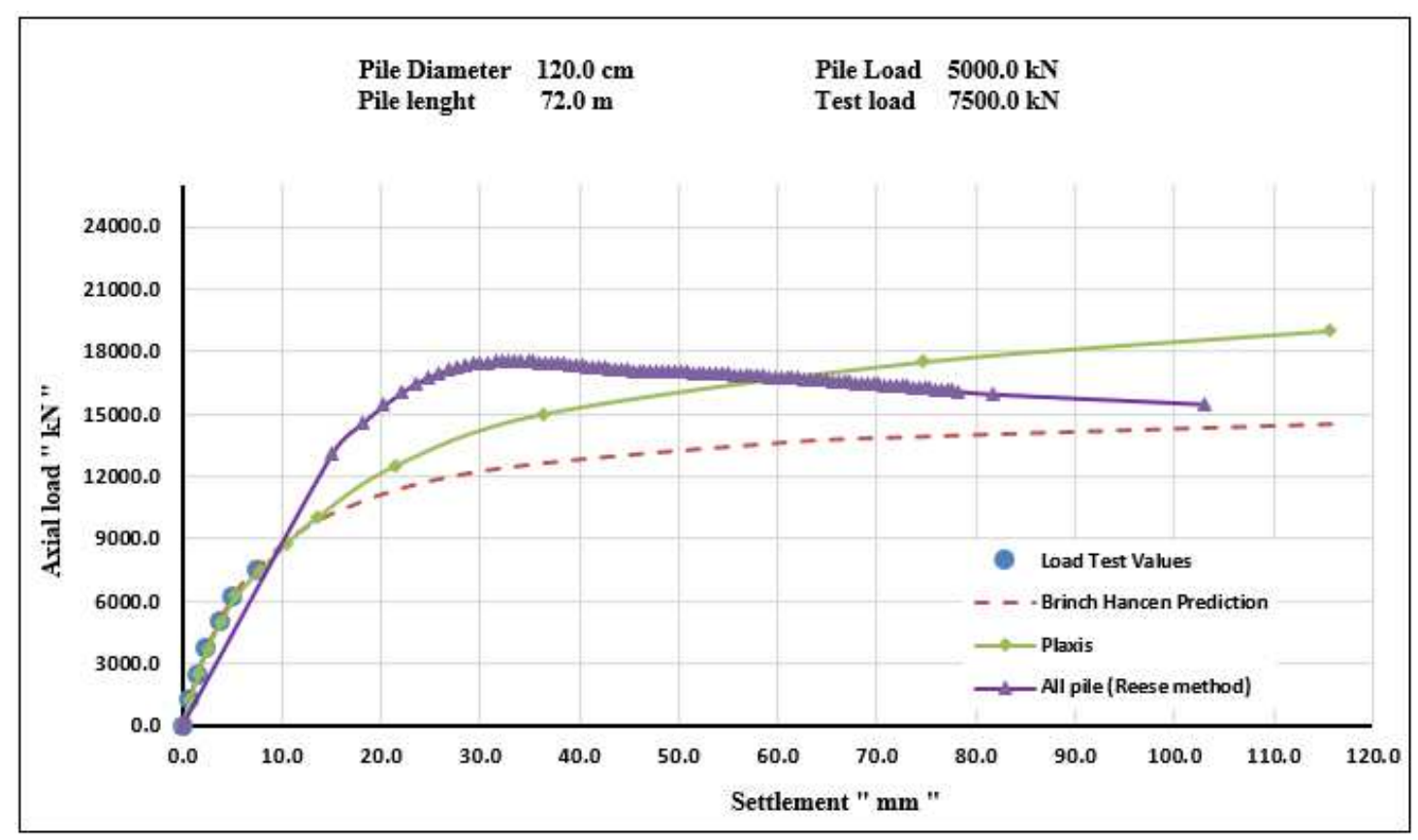

Fig. 5: Comparison between field test and finite element analysis in loading cycle for model No 2 


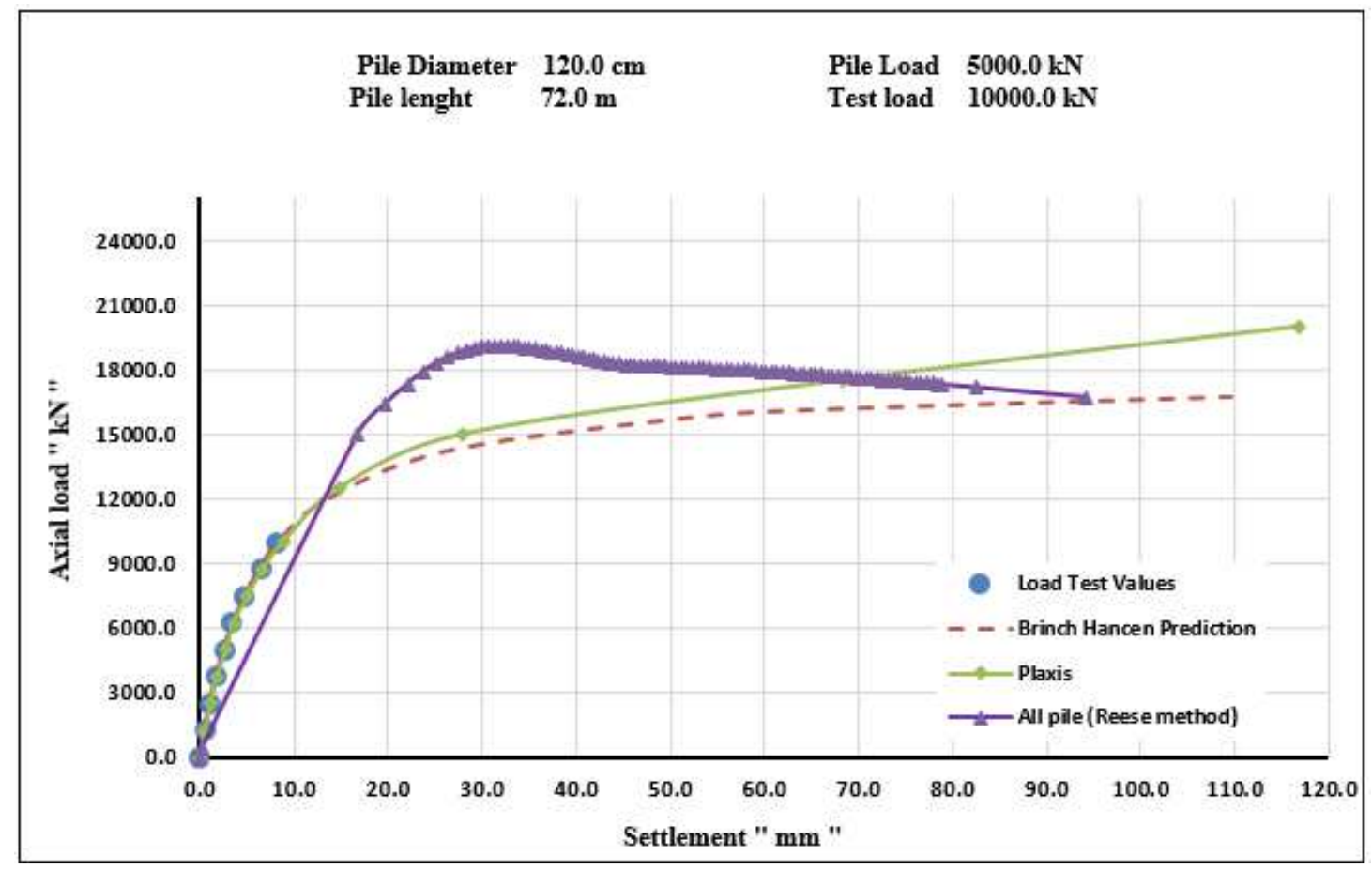

Fig. 6: Comparison between field test and finite element analysis in loading cycle for model No 3

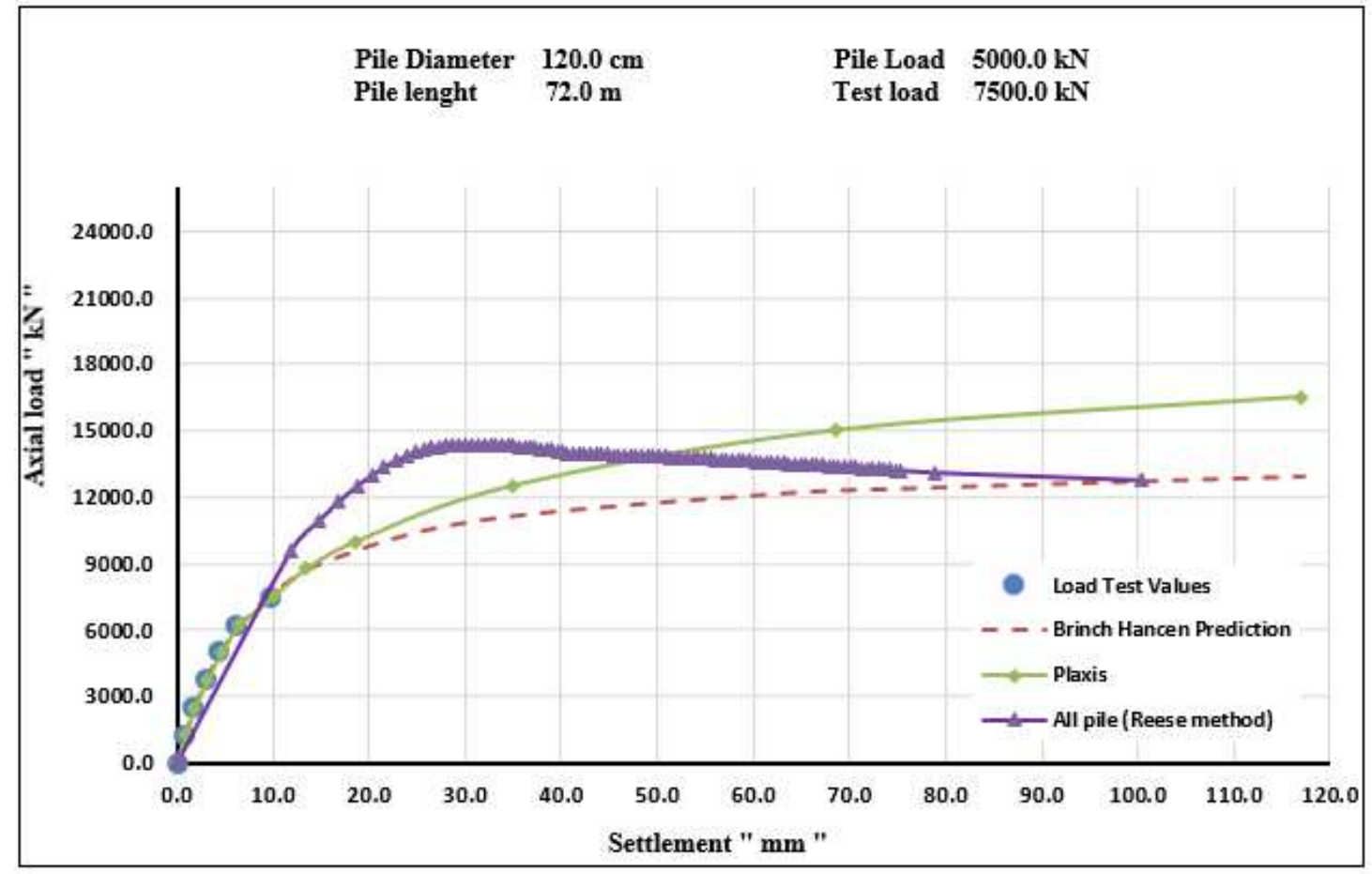

Fig. 7: Comparison between field test and finite element analysis in loading cycle for model No 4 


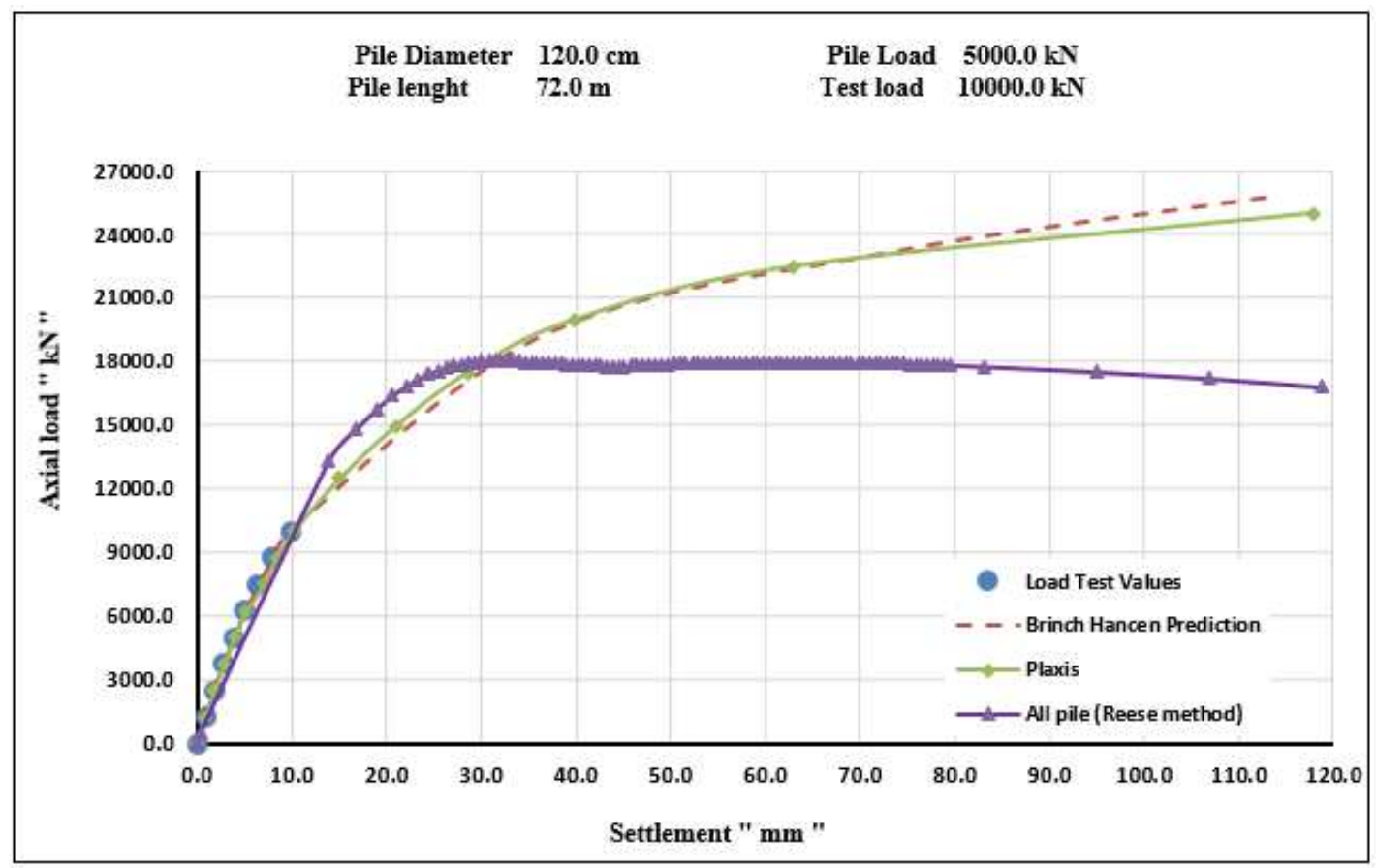

Fig. 8: Comparison between field test and finite element analysis in loading cycle for model No 5

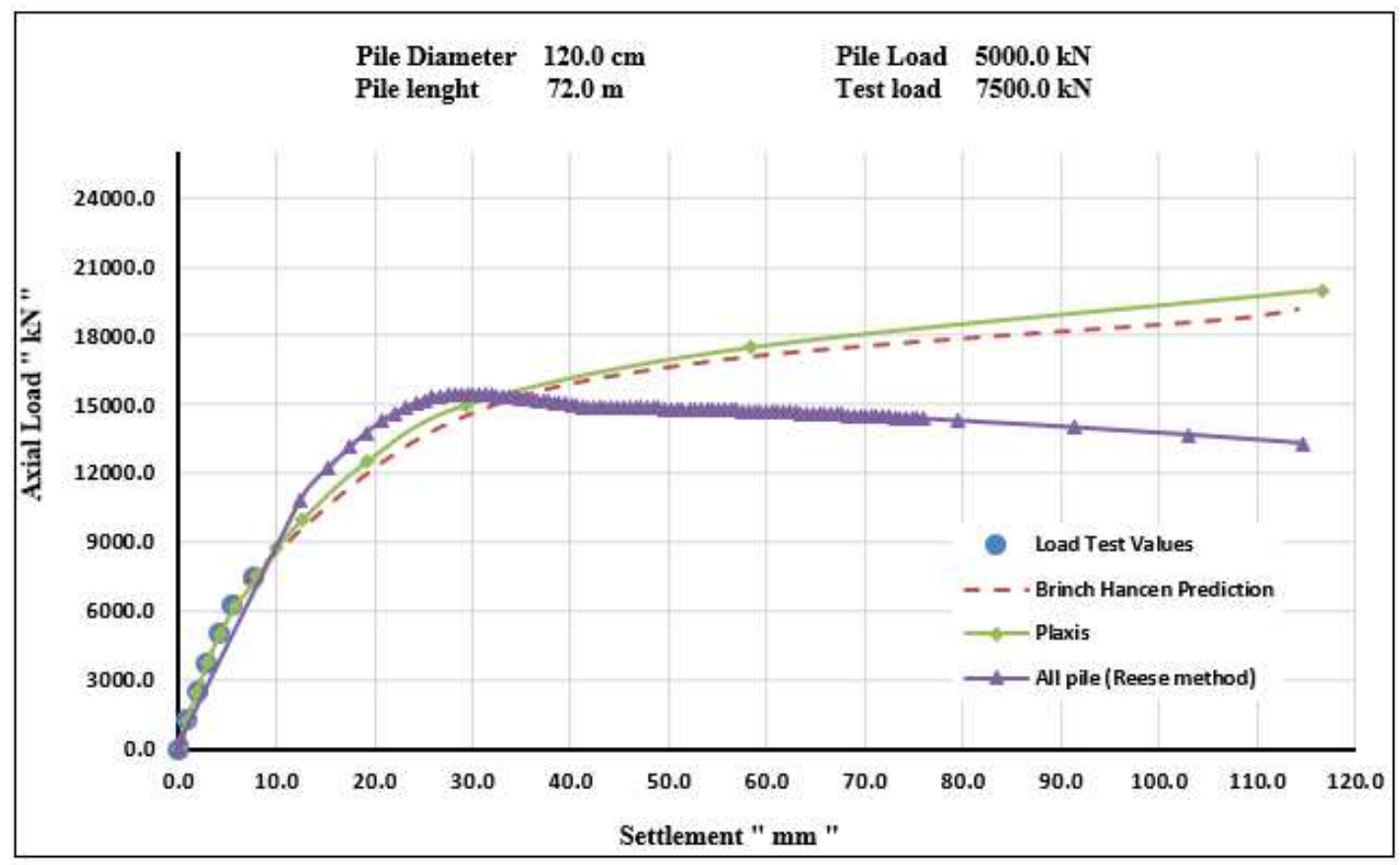

Fig. 9: Comparison between field test and finite element analysis in loading cycle for model No 6 


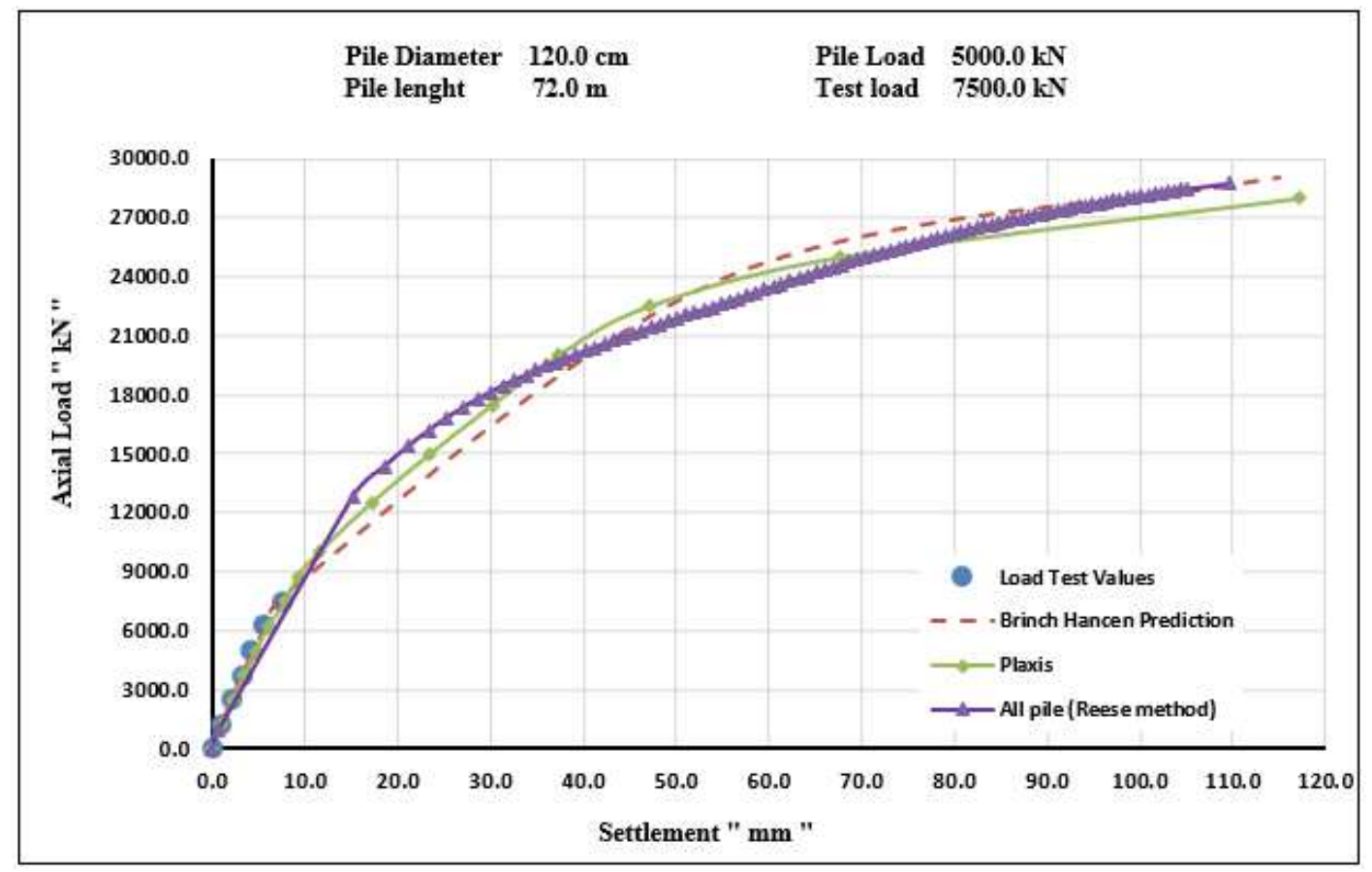

Fig. 10: Comparison between field test and finite element analysis in loading cycle for model No 7

Next figures show for the same tests the comparison between the loading-unloading curves of the experiment versus numerical prediction. Again, the figures show very good comparisons and give confidence on the reliability of the developed numerical models for future prediction.

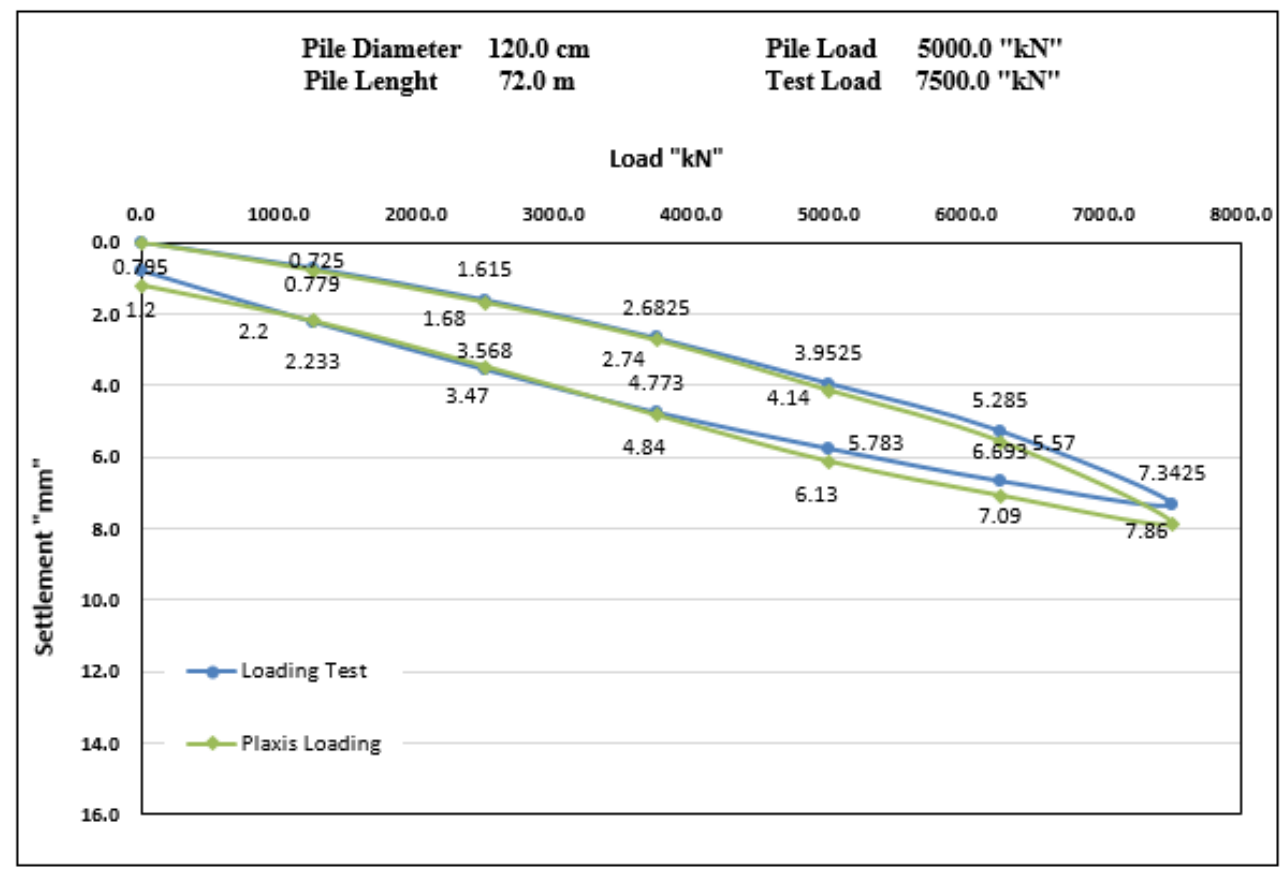

Fig.11. Comparison between field test and finite element analysis in loading-unloading cycle for model No 1 
SIMULATION BETWEEN IN-SITU PILE LOAD TEST AND NUMERICAL ANALYSIS OF LARGE DIAMETER BORED PILE IN PORT SAID EAST PORT-EGYPT

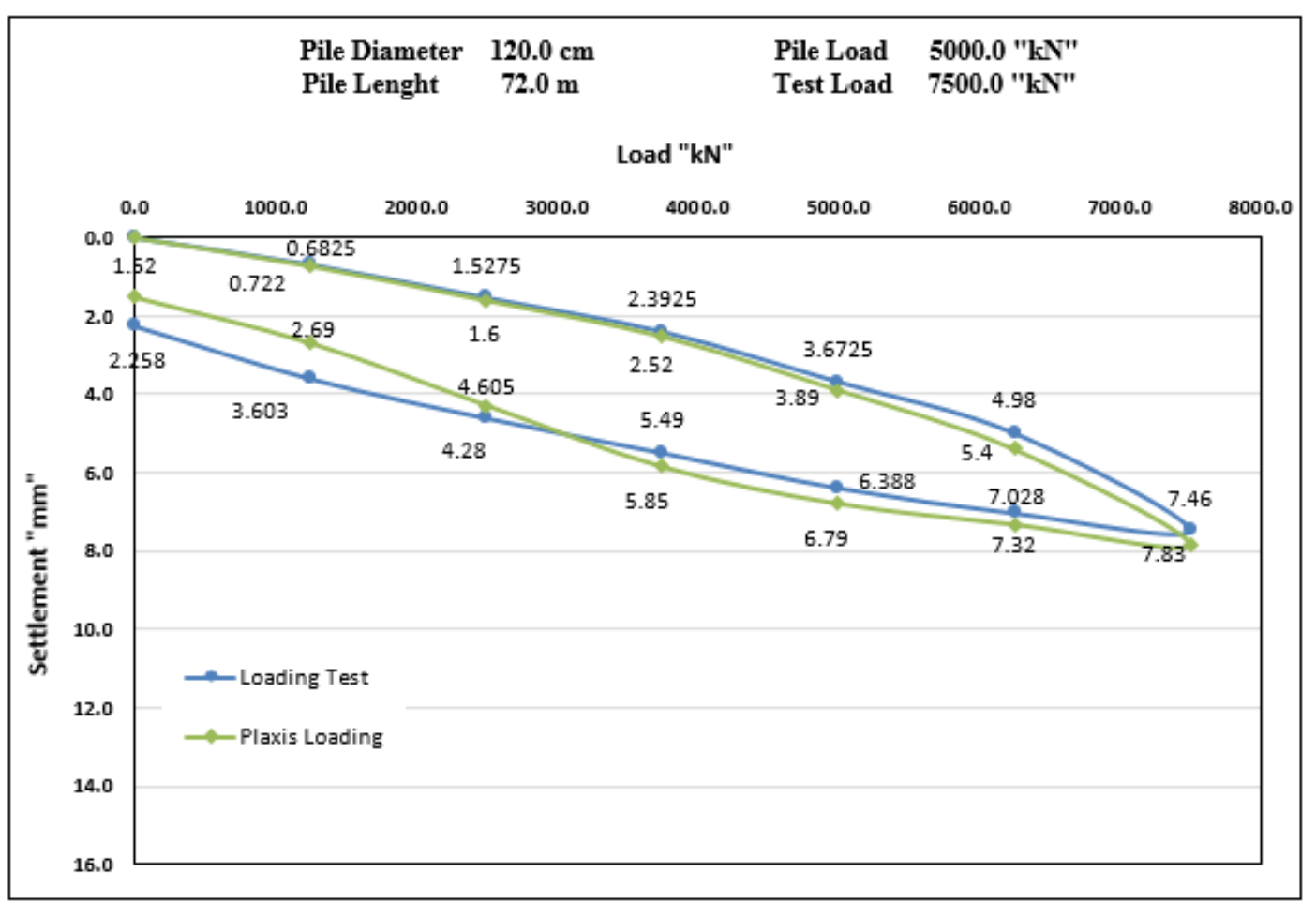

Fig.12. Comparison between field test and finite element analysis in loading-unloading cycle for model No 2

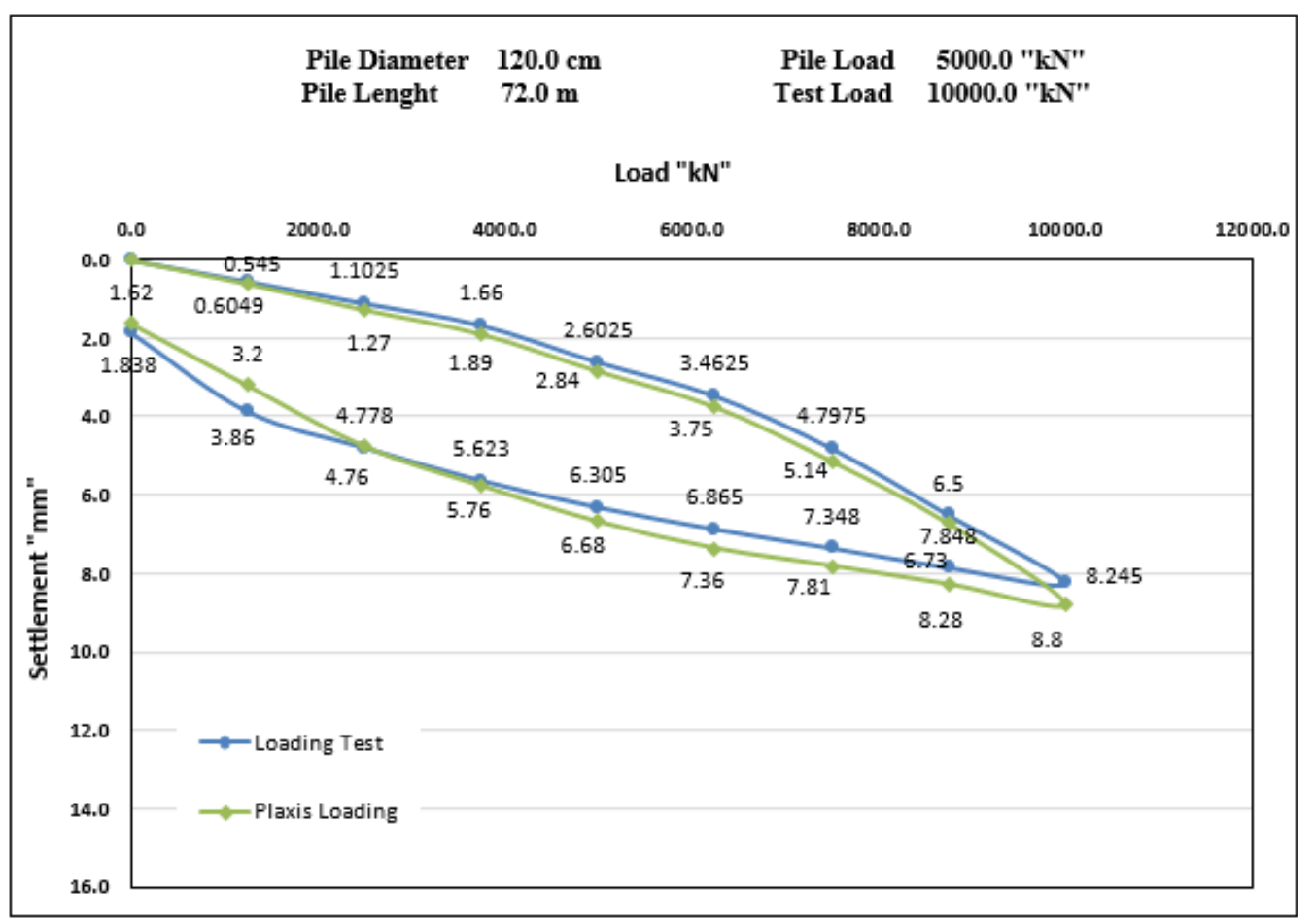

Fig.13. Comparison between field test and finite element analysis in loading-unloading cycle for model No 3 
SIMULATION BETWEEN IN-SITU PILE LOAD TEST AND NUMERICAL ANALYSIS OF LARGE DIAMETER BORED PILE IN PORT SAID EAST PORT-EGYPT

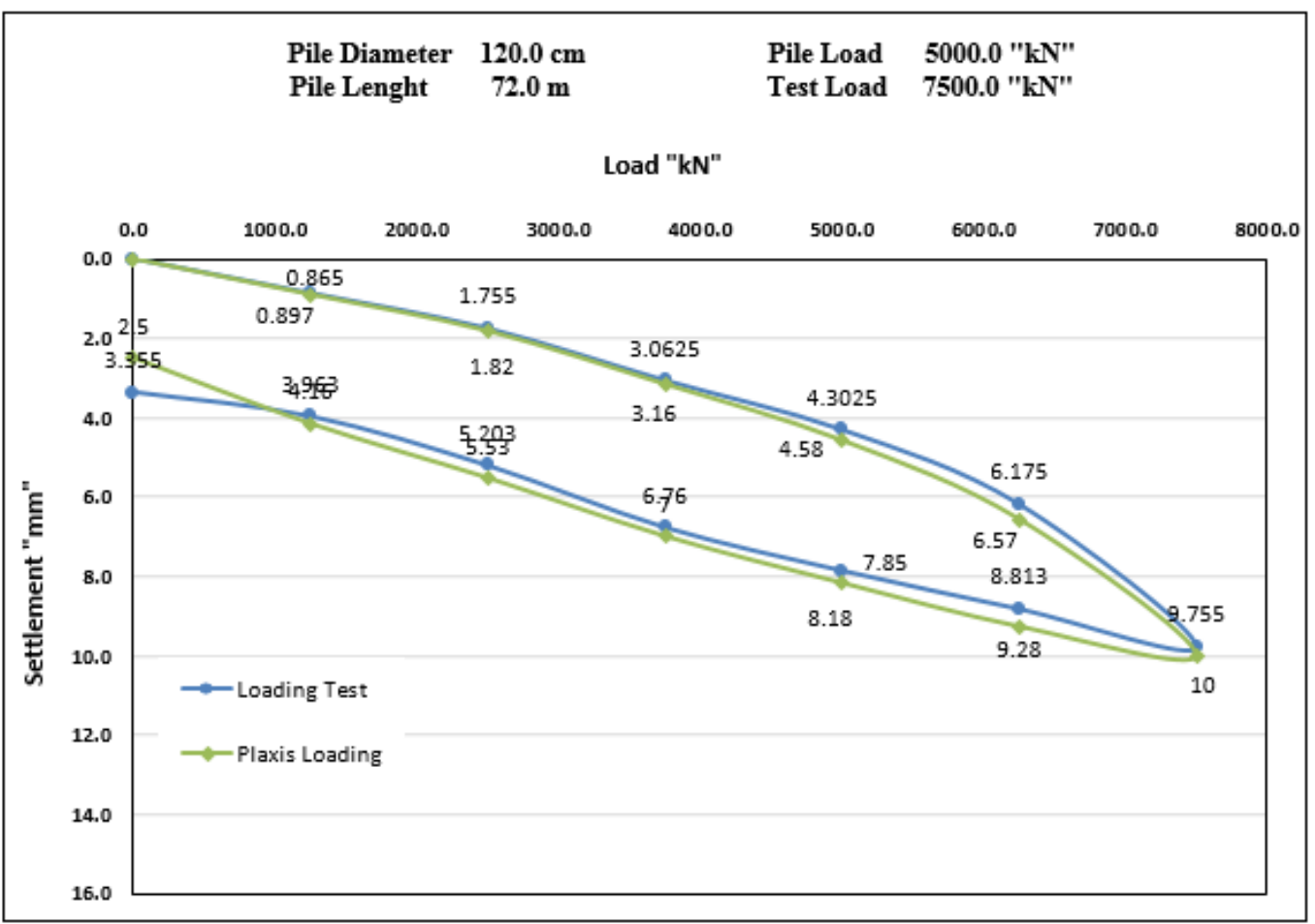

Fig.14. Comparison between field test and finite element analysis in loading-unloading cycle for model No 4

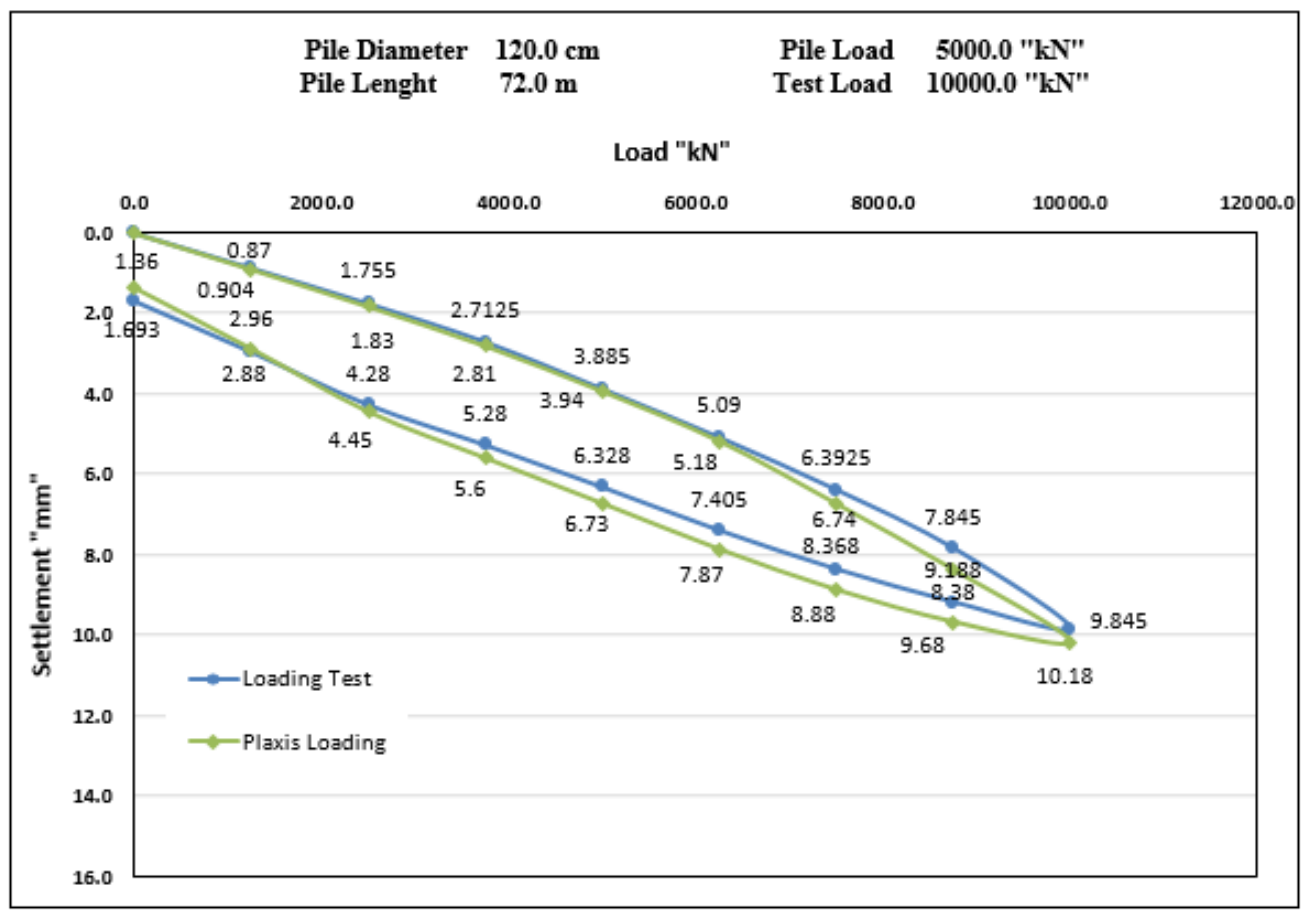

Fig.15. Comparison between field test and finite element analysis $\mathbf{n}$ loading-unloading cycle for model No 5 


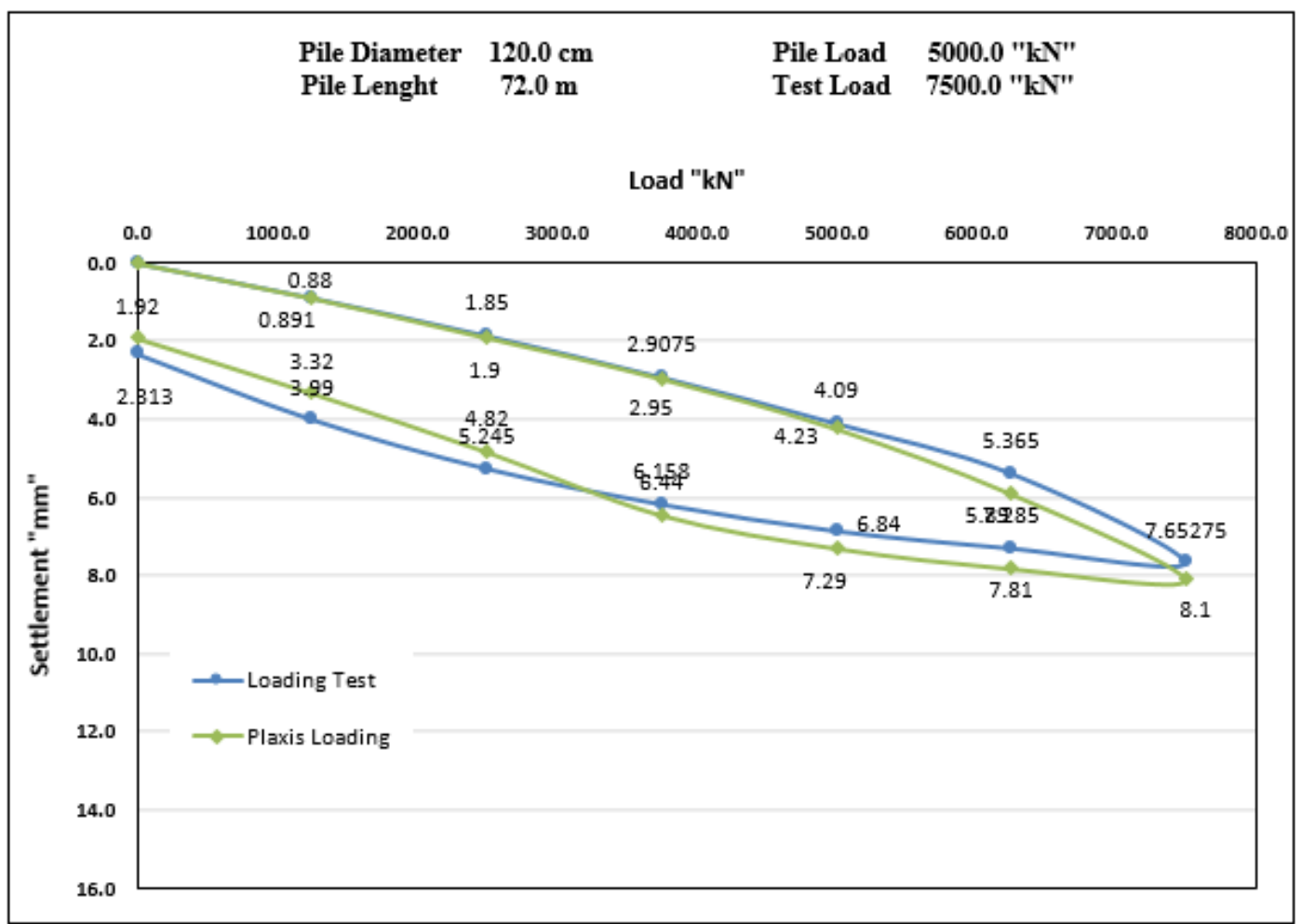

Fig.16. Comparison between field test and finite element analysis in loading-unloading cycle for model No 6

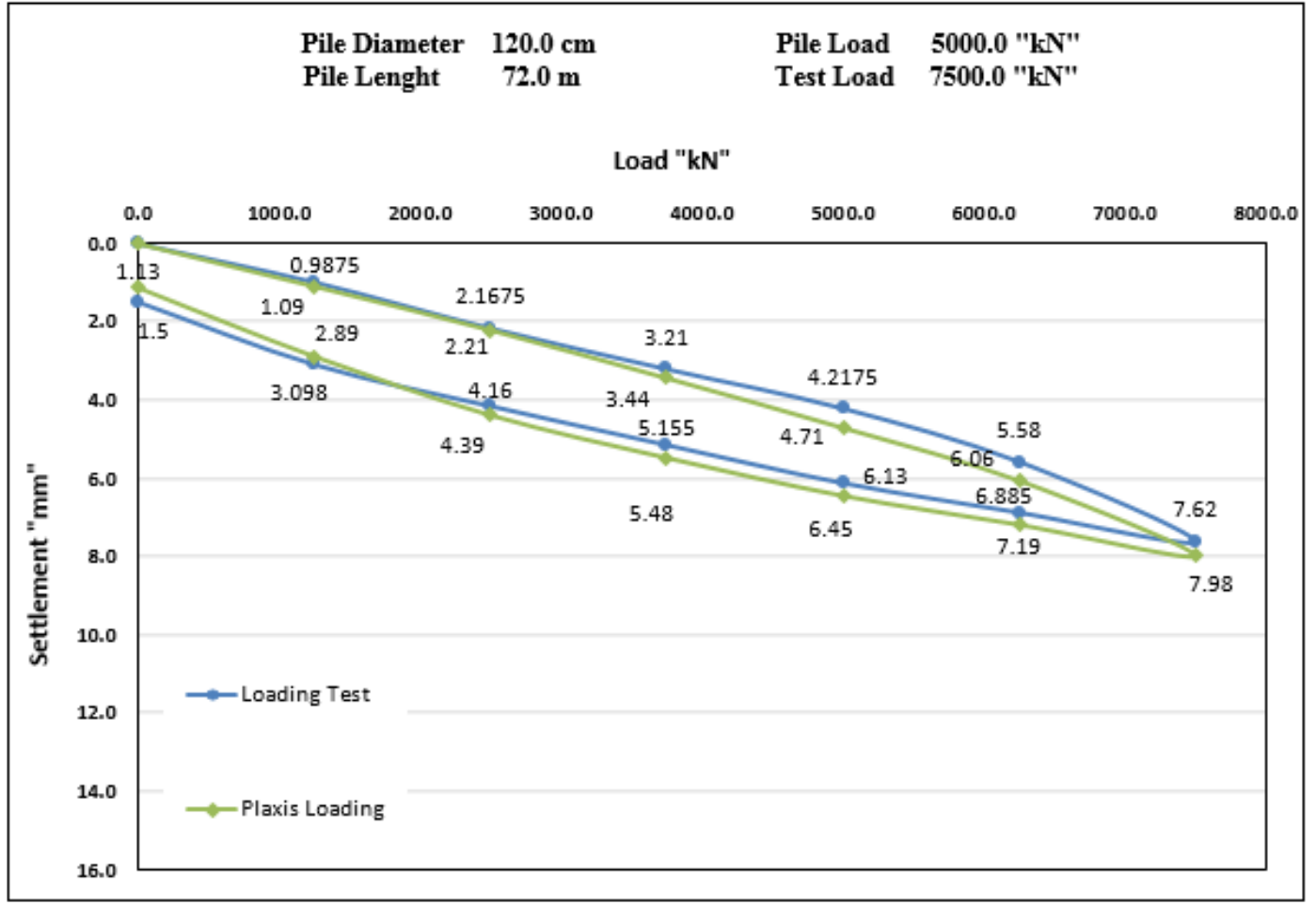

Fig.17. Comparison between field test and finite element analysis in loading-unloading cycle for model No 7

As shown in the previous figures, it can be seen that good agreement is obtained between field measurements and numerical analysis at all stages of the loading-unloading cycles through loading stage; especially from the first stage until achieved to test load (10000 KN). 
Table 5, shows settlement comparison between static load test, All pile and PLAXIS at three loading stages: the design load Q, one and half of the design load 1.5 Q and twice the design load 2Q for the loading-unloading cycles.

Table 5: results of settlement for loading tests and numerical analyses

\begin{tabular}{|c|c|c|c|c|c|c|c|c|c|c|}
\hline \multirow{3}{*}{ 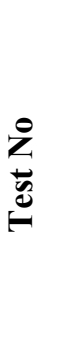 } & \multirow{3}{*}{$\begin{array}{l}\stackrel{0}{Z} \\
\frac{0}{0} \\
\stackrel{0}{g}\end{array}$} & \multicolumn{9}{|c|}{ Loading cycle } \\
\hline & & \multicolumn{3}{|c|}{ Design load "Q" } & \multicolumn{3}{|c|}{ Test load "1.5 Q" } & \multicolumn{3}{|c|}{ Test load "2 Q" } \\
\hline & & 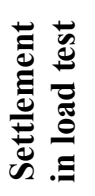 & 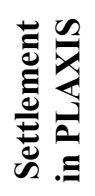 & 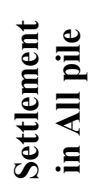 & 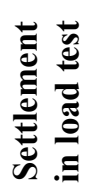 & 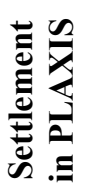 & 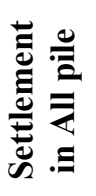 & 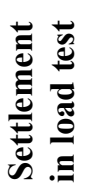 & 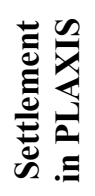 & 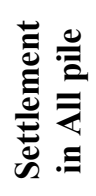 \\
\hline & units & $\mathrm{mm}$ & $\mathrm{mm}$ & $\mathrm{mm}$ & $\mathrm{mm}$ & $\mathrm{mm}$ & $\mathrm{mm}$ & $\mathrm{mm}$ & $\mathrm{mm}$ & $\mathrm{mm}$ \\
\hline 1 & 2 & 3.95 & 4.14 & 5.73 & 7.34 & 7.86 & 8.7 & ---- & ---- & ---- \\
\hline 2 & 3 & 3.67 & 3.89 & 5.78 & 7.46 & 7.83 & 8.8 & $\begin{array}{l}--- \\
--\end{array}$ & $\begin{array}{l}--- \\
\end{array}$ & $\begin{array}{l}--- \\
\end{array}$ \\
\hline 3 & 4 & 2.60 & 2.84 & 5.52 & 4.79 & 5.14 & 8.50 & 8.24 & 8.80 & 12.10 \\
\hline 4 & 6 & 4.30 & 4.74 & 6.19 & 9.75 & 9.84 & 9.55 & ---- & ---- & ---- \\
\hline 5 & 7 & 3.88 & 3.94 & 5.13 & 6.39 & 6.74 & 7.85 & 9.84 & 10.18 & 10.72 \\
\hline 6 & 9 & 4.09 & 4.23 & 5.61 & 7.65 & 8.10 & 8.55 & ---- & --- & ---- \\
\hline 7 & 10 & 4.22 & 4.71 & 5.67 & 7.62 & 7.98 & 8.8 & ---- & ---- & ---- \\
\hline
\end{tabular}

Table 6: results of settlement for unloading tests and numerical analyses

\begin{tabular}{|c|c|c|c|c|c|}
\hline \multirow{3}{*}{$\begin{array}{l}\stackrel{0}{Z} \\
\stackrel{\Delta}{\underline{\Delta}}\end{array}$} & \multirow{3}{*}{ 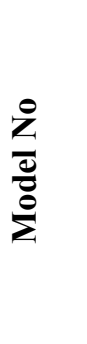 } & \multicolumn{4}{|c|}{ Unloading cycle } \\
\hline & & \multicolumn{2}{|c|}{ Design load "Q" } & \multicolumn{2}{|c|}{ Test load "1.5 Q" } \\
\hline & & 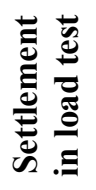 & 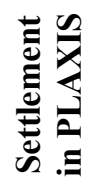 & 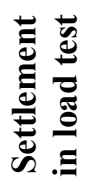 & 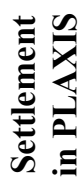 \\
\hline & units & $\mathrm{mm}$ & $\mathrm{mm}$ & $\mathrm{mm}$ & $\mathrm{mm}$ \\
\hline 1 & 2 & 5.78 & 6.13 & 7.34 & 7.86 \\
\hline 2 & 3 & 6.38 & 6.79 & 7.46 & 7.83 \\
\hline 3 & 4 & 6.30 & 6.68 & 7.35 & 7.81 \\
\hline 4 & 6 & 7.85 & 7.97 & 9.75 & 9.84 \\
\hline 5 & 7 & 6.33 & 6.73 & 8.37 & 8.88 \\
\hline 6 & 9 & 6.84 & 7.29 & 7.65 & 8.1 \\
\hline 7 & 10 & 6.13 & 6.45 & 7.62 & 7.98 \\
\hline
\end{tabular}


Table 7: Summary of compared settlement percentages between software program and results of field loading tests.

\begin{tabular}{|c|c|c|c|c|}
\hline & $\frac{\Delta \text { field }}{\Delta \text { program }} \%$ & $\begin{array}{c}\text { At pile design } \\
\text { load "Q" }\end{array}$ & $\begin{array}{c}\text { At pile test load } \\
\text { "150\% Q" }\end{array}$ & $\begin{array}{c}\text { At pile test load } \\
\text { "200\% Q" }\end{array}$ \\
\hline \multirow{2}{*}{$\begin{array}{c}\text { Loading } \\
\text { cycle }\end{array}$} & PLAXIS & $(89.5-98.5) \%$ & $(93.2-99) \%$ & $(93.6-96.6) \%$ \\
\cline { 2 - 5 }$\%$ & All pile & $(74.5-75.6) \%$ & $(56.4-89.5) \%$ & $(68.1-91.8) \%$ \\
\hline $\begin{array}{c}\text { Un loading } \\
\text { cycle }\end{array}$ & PLAXIS & $(93.9-98.5) \%$ & $(93.2-99) \%$ & $(93.6-96.6) \%$ \\
\hline
\end{tabular}

\section{CONCLUSIONS}

The paper calibrates commonly used software (PLAXIS) and (All pile) programs using seven in-situ pile loading tests. Based on the research work presented in the study, the following conclusions were observed:

- Very good agreement was obtained between numerical simulation using PLAXIS and in-situ pile load test for loading and unloading cycles.

- The percentage of compatibility is about $95 \%$ between numerical analyses using PLAXIS and field load tests. But this ratio reduced to $75 \%$ when using All pile program.

- The load- settlement curves of bored pile in all tests using All Pile program is so far in comparison with loading tests.

- Predicting the apparent failure in the felid loading tests of large diameter bored pile is very difficult due to the large loads carried by these piles.

- Ultimate load capacity for piles, determined by numerical model is in good agreement with the average load estimated from Chin (1970) and Hansen (1963) methods.

\section{REFERENCE}

1. AASHTO. (1998), "LRFD Bridge Design Specification", SI units, Second Edition.

2. ASTM. (2007), "Standard test method for piles under static axial compressive load", ASTM D 1143-07.

3. Brinkgreve, R.B.J. and Broere W. (2004)," PLAXIS 2D Manual", Netherlands.

4. Chin, F.K. (1970), "Estimation of the Ultimate Load of Piles Not Carried to Failure". Proceedings of the Second Southeast Asian Conference on Soil Engineering 'Singapore, pp. 81-90.

5. Civil Tech Software, "All Pile Manual", U.S. and Canada.

6. DIN 4014. (1990), "German association for earthworks and foundation engineering", Deutsches Institute fur Normung, Berlin, Germany.

7. ECP 202/3. (2005), "Egyptian code for soil mechanics - design and construction of foundations. Part 3, Shallow Foundation". The Housing and Building Research Center (HBRC), Cairo, Egypt.

8. ECP 202/4. (2005), "Egyptian code for soil mechanics - design and construction of foundations. Part 4, Deep foundations", The Housing and Building Research Center (HBRC), Cairo, Egypt.

9. Ezzat, M., Eid, M., Hefny, A., Sorour, T. and Zaghloul, Y. (2019), "Numerical Analysis of Large Diameter Bored Pile Installed in Multi Layered Soil: A Case Study of Damietta Port New Grain Silos Project", International Journal of Current Engineering and Technology, vol 13, No 9.

10. Hansen, J. B. (1963), "Discussion on hyperbolic stress-strain response in cohesive soils". ASCE, Vol. 89, SM4, pp. 241-242.

11. Kulhawy, F.H. (1991), "Drilled shaft foundations", foundation engineering handbook, 2nd Ed., H. Y. Fang, ed., Van Nostrand-Reinhold, New York.

12. Kulhawy, F. H., and Mayne, P. W. (1990), "Manual on estimating soil properties for 
foundation design", Rep. No. EPRI EL-6800, Electric Power Research Institute, Palo Alto, Calif. 2-25.

13. Moayedi, H. Kalantar, B. Abdullahi, M. Rashid, A. Nazir,R and Nguyen,H. (2019), "Determination of Young Elasticity Modulus in Bored Piles Through the Global Strain Extensometer Sensors and Real-Time Monitoring Data", Applied science (Switzerland), vol9.

14. O'Neill, M. W., Reese, and R. C. (1999), "Drilled Shafts: construction procedures and design methods", federal highway administration, Washington, D.C.

15. Teshome, F., and Ismail, A. (2011), "Analysis of deformations in soft clay due to unloading". Master's Thesis, Department of Civil and Environmental Engineering Division of Geoengineering, Chalmers Uni.

16. Wehnert, M. and Vermeer, P. A. (2004), "Numerical Analyses of Load Tests on Bored Piles", Numerical Method in Geomechanics-NUMOG IX, pp. 505-511. 